\title{
Convergent Surface Water Distributions in U.S. Cities
}

\author{
M. K. Steele, ${ }^{1 *}$ J. B. Heffernan, ${ }^{1}$ N. Bettez, ${ }^{2}$ J. Cavender-Bares, ${ }^{3}$ \\ P. M. Groffman, ${ }^{2}$ J. M. Grove, ${ }^{4}$ S. Hall, ${ }^{5}$ S. E. Hobbie, ${ }^{3}$ K. Larson, ${ }^{6}$ \\ J. L. Morse, ${ }^{7}$ C. Neill, ${ }^{8}$ K. C. Nelson,,${ }^{9,10}$ J. O’Neil-Dunne, ${ }^{11}$ L. Ogden, ${ }^{12}$ \\ D. E. Pataki, ${ }^{13}$ C. Polsky, ${ }^{14}$ and R. Roy Chowdhury ${ }^{15}$
}

\begin{abstract}
${ }^{1}$ Nicholas School of the Environment, Duke University, Durham, North Carolina, USA; ${ }^{2}$ Cary Institute of Ecosystem Studies, Millbrook, New York, USA; ${ }^{3}$ Department of Ecology, Evolution, and Behavior, University of Minnesota, Minneapolis, Minnesota, USA; ${ }^{4}$ USDA Forest Service, Baltimore Field Station, Baltimore, Massachusetts, USA; ${ }^{5}$ Ecology, School of Life Sciences, Arizona State University, Phoenix, Arizona, USA; ${ }^{6}$ Schools of Geographical Sciences and Urban Planning and Sustainability, Arizona State University, Phoenix, Arizona, USA; ${ }^{7}$ Portland State University, Portland, Oregon, USA; ${ }^{8}$ The Ecosystems Center Marine Biological Laboratory, Woods Hole, Minnesota, USA; ${ }^{9}$ Department of Forest Resources, University of Minnesota, Minneapolis, Minnesota, USA; ${ }^{10}$ Department of Fisheries, Wildlife, and Conservation Biology, University of Minnesota, Minneapolis, Minnesota, USA; ${ }^{11}$ Spatial Analysis Lab, Rubenstein School of Environment and Natural Resources, University of Vermont, Burlington, Vermont, USA;

${ }^{12}$ Department of Global \& Sociocultural Studies, Florida International University, St. Miami, Florida, USA; ${ }^{13}$ Department of Biology, University of Utah, Salt Lake City, Utah, USA; ${ }^{14}$ Graduate School of Geography, Clark University, Worcester, Massachusetts, USA;

${ }^{15}$ Department of Geography, Indiana University, Bloomington, Indiana, USA
\end{abstract}

\begin{abstract}
Earth's surface is rapidly urbanizing, resulting in dramatic changes in the abundance, distribution and character of surface water features in urban landscapes. However, the scope and consequences of surface water redistribution at broad spatial
\end{abstract}

Received 5 June 2013; accepted 15 January 2014;

published online 19 February 2014

Electronic supplementary material: The online version of this article (doi:10.1007/s10021-014-9751-y) contains supplementary material, which is available to authorized users.

Author Contributions:: MK Steele: performed research, analyzed data, contributed new methods or models, wrote the paper; JB Heffernan: conceived of or designed study, analyzed data, wrote the paper; N Bettez: wrote the paper; J Cavender-Bares: conceived of or designed study, wrote the paper; PM Groffman: conceived of or designed study, wrote the paper; JM Grove: conceived of or designed study; S Hall: conceived of or designed study, wrote the paper; SE Hobbie: conceived of or designed study, wrote the paper; K Larson: wrote the paper; JL Morse: wrote the paper; C Neill: conceived of or designed study; KC Nelson: conceived of or designed study, wrote the paper; J O'Neil-Dunne: conceived of or designed study, wrote the paper; L Ogden: conceived of or designed study, wrote the paper; DE Pataki: conceived of or designed study, wrote the paper; C Polsky: conceived of or designed study; R Roy Chowdhury: conceived of or designed study, wrote the paper.

*Corresponding author; e-mail: meredith.steele@vt.edu scales are not well understood. We hypothesized that urbanization would lead to convergent surface water abundance and distribution: in other words, cities will gain or lose water such that they become more similar to each other than are their surrounding natural landscapes. Using a database of more than 1 million water bodies and 1 million $\mathrm{km}$ of streams, we compared the surface water of 100 US cities with their surrounding undeveloped land. We evaluated differences in areal $\left(A_{\mathrm{WB}}\right)$ and numeric densities $\left(N_{\mathrm{WB}}\right)$ of water bodies (lakes, wetlands, and so on), the morphological characteristics of water bodies (size), and the density $\left(D_{\mathrm{C}}\right)$ of surface flow channels (that is, streams and rivers). The variance of urban $A_{\mathrm{WB}}, N_{\mathrm{WB}}$, and $D_{\mathrm{C}}$ across the 100 MSAs decreased, by 89,25 , and $71 \%$, respectively, compared to undeveloped land. These data show that many cities are surface water poor relative to undeveloped land; however, in drier landscapes urbanization increases the occurrence of surface water. This convergence pattern strengthened with development intensity, such that high intensity urban development had an areal water body density $98 \%$ less than undeveloped lands. Urbanization appears to drive the convergence of 
hydrological features across the US, such that surface water distributions of cities are more similar to each other than to their surrounding landscapes.
Key words: surface water; urbanization; cities; convergence; urban streams; urban water bodies; hydrography.

\section{INTRODUCTION}

Surface water plays contrasting roles in cities, both supporting and hindering development of urban landscapes. Streams, rivers, lakes, ponds, and wetlands within urban environments can be important components of water supply and flood control systems; and they provide additional ecosystem services including recreational and aesthetic value (Bolund and Hunhammar 1999), species habitat (Hamer and Parris 2011; McKinney and others 2011), microclimate moderation (Sun and others 2012; Sun and Chen 2012), and removal of pollutants (Grimm and others 2008b). However, when urban land is scarce relative to demand for development, the space occupied by surface water is valuable and often subject to alteration to promote development ( $\mathrm{Du}$ and others 2010). In addition, surface water can create flooding risks and other hazards to surrounding land, structures, and populations. To increase the area of urban land and control water supply and drainage, humans drain, fill, and bury surface water features. This practice has resulted in substantial loss of stream channels in cities in mesic regions (Elmore and Kaushal 2008; Roy and others 2009; Pataki and others 2011). Alternatively, construction of lakes, ponds, and canals can also increase surface water abundance, particularly of cities in arid regions (Larson and Grimm 2012). However, little attention has been paid to hydrographic change at broader spatial scales, where distinct patterns and processes may emerge (Heffernan and others 2014; Thorp 2014). A broader assessment of how urbanization changes the channel and water body abundance, distribution, and form (hydrography) in cities is essential to understanding both the environmental constraints on land-use change (Dunne and Leopold 1978) and the environmental and societal consequences of rapid and ongoing urbanization of human populations and landscapes (Paul and Meyer 2001; Cohen 2003; Foley and others 2005; Kareiva 2007; Grimm and others 2008a).

We contend that the value of surface water features in urban environments, relative to dry land, increases as a function of their scarcity. Accordingly, we hypothesize that this relationship drives patterns in the alteration of urban surface water distributions. If true, the difference in surface water coverage between urban and surrounding undeveloped land should be positive (urban $>$ undeveloped), where surface water is rare, but negative (urban < undeveloped) where it is abundant. As a result, urbanization at continental scales should lead to lower variation in surface water abundance across cities relative to variation among their surrounding undeveloped hydroscapes. This pattern would show that urban surface water converges on a specific form, as observed in the constructed components of the urban environment (Seto and Fragkias 2005). Moreover, these patterns should be strongest in intensely developed urban areas, where land is most highly altered.

The objective of this study was to compare the characteristics of surface water (hydrography) of urban land cover to that of surrounding undeveloped land. We investigated urban hydrography using a database of more than 1 million water bodies (that is, lakes, ponds, wetland, marshes, reservoirs) and 1 million $\mathrm{km}$ of stream channels from 100 Metropolitan Statistical Areas (MSAs). Hydrographic measures of \% water body coverage $\left(A_{\mathrm{WB}}\right)$, water body density $\left(N_{\mathrm{WB}}\right)$, and channel density $\left(D_{\mathrm{C}}\right)$ for each land cover type were calculated using surface water features from the $\mathrm{Na}$ tional Hydrography Dataset. These hydrographic characteristics were compared to the surrounding land cover in each MSA.

\section{METHODS}

We selected 100 cities with a defined MSA from the continental United States. The United States Office of Management and Budget defines an MSA as an urban core with population of at least 50,000 and associated counties with a high degree of social and economic integration (as measured by commuting to work) with the urban core (Census Bureau 2012). To ensure a representative sample of continental US cities, cities were categorized by their designated ecological regions as established by the National Ecological Observatory Network (NEON 2010). The number of MSAs selected from each ecological region was weighted based on the proportion of MSAs present. Cities were also categorized by population size into five groups. Within each eco-region, cities were randomly selected to generate roughly equal representation from each 
population group, so the MSAs were dispersed through the eco-region. Six cities were specifically included as part of a broader study of urban homogenization (Groffman and others 2014). Otherwise, cities were chosen "blind" to avoid biases (that is, the selector did not know the name of the MSA/city during selection). This method was chosen over a completely randomized selection process because cities with small populations in the US are more abundant than larger cities. Our selection process provided a more balanced distribution across population gradients.

We categorized land cover in each MSA using the 2006 National Land Cover Data (NLCD). The NLCD classes were grouped into five categories: urban open area $(\mathrm{NLCD}=21)$, urban low intensity $(\mathrm{NLCD}=22)$, urban medium intensity (NLCD $=23)$, urban high intensity $(\mathrm{NLCD}=24)$, agriculture $(\mathrm{NLCD}=81,82)$, and "undeveloped" (all remaining NLCD). Using ArcGIS (v10) we calculated the majority land cover of every census block group (CBG) in the MSA. In the few instances where water (a land-cover category in the NLCD) was calculated as the majority land cover in a CBG, the non-water land cover was assigned by hand based on the classification of the surrounding CBGs. The water coverage from NLCD was not used in any further analysis.

Surface water data layers were obtained from the National Hydrography Dataset (NHD). Features included inland water bodies (that is, lakes/ponds, reservoirs, swamps/marshes), those in coastal and estuarine systems, and surface flow lines. The maximum resolution of the NHD high-resolution data is 1:5,000, but varies by state. Although there is no known estimate of the percentage of missing water bodies from this dataset, we recognized that the number of missing stream channels may be as high as $78 \%$ at this scale (Roy and others 2009). The length of streams converted to storm drains or buried underground are likely more dense in urbanized areas and no longer appear in this data as streams; however, there is no evidence that the errors of omission for streams are greater in urban areas. Despite its limitations, NHD remains the most comprehensive coverage at the national scale. NHD uses feature codes (FCodes) to categorize water bodies in to different feature domains. FCodes in this study were grouped into several different classes: perennial lakes and ponds, intermittent lakes and ponds, swamps and marshes, water storage reservoirs, other reservoirs, perennial streams and rivers, intermittent and ephemeral streams and rivers, and canals/ditches.

The hydrography data layers were intersected with the CBG land-cover layer to categorize each feature by its surrounding land cover. For the undeveloped land we used the NHD feature point data to locate all of the water bodies with dams in the undeveloped land class. The NHD data contains the location of dams in the United States, primarily based on the National Dam Inventory; however, only larger dams are included in this study (see Army Corps of Engineers (2013) for full description of criteria). Dammed water bodies were identified by the points that intersected the water bodies with a $10 \mathrm{~m}$ buffer to account for minor mapping variations. Intermittent water bodies were also removed so that only perennial features were included. Otherwise, for each land-cover category, we summed the number and area of water bodies and then divided by the total land area in each category to calculate the density of water bodies and the percentage of area covered by water. We summed the channel lengths and divided by land area to calculate channel density.

\section{Water Body Size Distributions}

To assess the convergence of water body characteristics, we analyzed the effect of land cover on water body size distributions $\left(S D_{\mathrm{WB}}\right)$. We calculated the median water body size in each land-cover type for all 100 MSAs. However, because the frequency distribution of water body sizes is poorly described by means or medians, we also described and compared these distributions based on Pareto distribution parameters. The shape of the Pareto distribution can be described by its slope $\left(\beta_{\text {Size }}\right)$, which becomes increasingly negative as the number of small water bodies increases (Downing and others 2006). We calculated $\beta_{\text {Size }}$ as the linear slope of the log-log transformed frequency distribution for all $n>$ size class $(x)$.

\section{Data Analysis}

Data analysis was conducted on the aggregate of the census block groups in each land category for every MSA. For example, to calculate percent water coverage we summed the area of all water bodies classified as "urban" in the MSA, and divided that sum by the total urban land area in the MSA. We compared the \% water body coverage $\left(A_{\mathrm{WB}}\right)$, water body density $\left(N_{\mathrm{WB}}\right)$, and channel density $\left(D_{\mathrm{C}}\right)$ of land-cover classes with a univariate analysis of variance and Tukey's post-hoc mean comparison. The $A_{\mathrm{WB}}, N_{\mathrm{WB}}$, and $D_{\mathrm{C}}$ data were logtransformed prior to analysis to normalize distributions. 
We define convergence as the process of becoming more similar such that differences between extremes decrease. We evaluated two predictions of the urban convergence hypothesis as it applies to hydrography: first, the variance of hydrographic parameters $(X=$ any hydrographic parameter) in the urban land cover is less than the variance of these parameters in the undeveloped land cover (Figure 1, Panel 1). Second, the difference between the undeveloped and urban land (the urban minus undeveloped value or " $\Delta X^{\prime \prime}$ ) must be positive at the low end of the range and negative at the high end of the range, assuming the value on which the parameters converge falls within the range of the undeveloped land (Figure 1, Panel 2). For example, if $A$ and $B$ represent high and low measures of undeveloped hydrographic parameters $\left(A_{\mathrm{WB}}, N_{\mathrm{WB}}, S D_{\mathrm{WB}}\right.$, or $\left.D_{\mathrm{C}}\right)$, while $A^{\prime}$ and $B^{\prime}$ represent the expected corresponding urban measure; as hydrography converges, $A^{\prime}$ and $B^{\prime}$ will have a more tightly constrained range. If convergence was not occurring $A^{\prime}$ and $B^{\prime}$ would fall closely to the 1:1 line (Figure 1, Panel 2). Hereafter, we use $\Delta A_{\mathrm{WB}}, \Delta N_{\mathrm{WB}}, \Delta S D_{\mathrm{WB}}$, and $\Delta D_{\mathrm{C}}$ as abbreviations for the difference between urban and undeveloped lands in terms of water body areal coverage, numeric density, size distribution, and channel density, respectively.

We tested for convergence indicators using two different estimates from the surrounding landscape to answer different questions regarding conver- gence. First, we compared urban versus non-urban land to test if urban hydroscapes are converging relative to all surrounding land, regardless of human alterations to the surrounding land. The nonurban land in this comparison included water bodies that originated from dams and those that occurred within agricultural development. Second, to test if urban hydroscapes are converging relative to minimally disturbed hydroscapes, we compared urban versus undeveloped land cover without dams. Although any space for time substitution limits the inferences regarding change, this comparison provides the best method for understanding how urban hydroscapes may have changed. We made this comparison without dams because we assume the hydrographic parameters (specifically $\left.A_{\mathrm{WB}}\right)$ without dams to be a more accurate estimate of the antecedent hydrography. Convergence of $A_{\mathrm{WB}}$ (the parameter most likely to be impacted by dams) was tested both with and without dams. We compared the degree of convergence in different urban land covers (open area, low, medium, and high intensity) using the undeveloped land cover without large dams. MSAs were also categorized by population size into three categories: small $(<250,000$ people, $n=33)$, medium $(250,000-1$ million people, $n=34)$, and large ( $>1$ million people, $n=33$ ). The convergence indicators were calculated for each population category.

To assess whether changes in the area of surface water were associated with changes in the

\section{Evidence of Convergence}

1. Variance decreases.

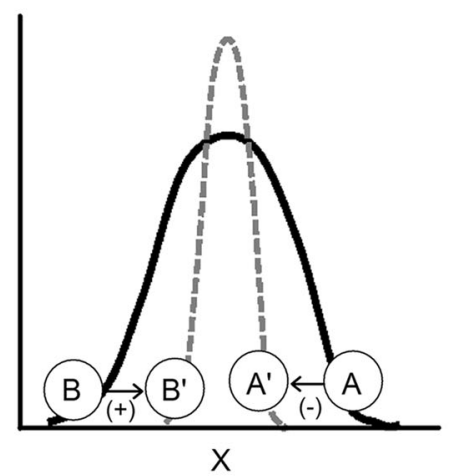

2. The positive or negative direction of $\triangle x$ depends on the antecedent conditions.

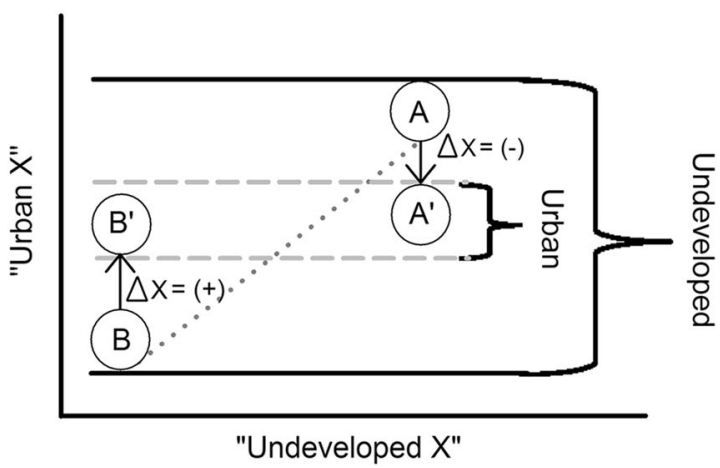

Figure 1. Conceptual model of convergence and the methods used to evaluate the evidence for our hypotheses: 1 the variance of hydrographic parameters will be lower for urban areas compared to undeveloped. $A$ and $B$ represent measures at the high and low end of the undeveloped range ( $X$ = hydrographic parameter), whereas $\mathrm{A}^{\prime}$ and $\mathrm{B}^{\prime}$ represent the expected corresponding urban measure. 2 If city hydrography converges, $A^{\prime}$ and $B^{\prime}$ will have a more tightly constrained range and difference between the urban and undeveloped land $(\Delta X)$ will be positive at the low end and negative at the high end of the undeveloped range. If convergence is not occurring $A^{\prime}$ and $B^{\prime}$ would be close to the $1: 1$ line (dotted line). 
number of water bodies, we examined the relationship between $\Delta A_{\mathrm{WB}}$ and $\Delta N_{\mathrm{WB}}$ across the 100 cities. A positive relationship between these variables would suggest that gain or loss of surface water occurs simply through the addition or removal of water features, but other combinations are possible. We categorized each city into one of four groups based on the values of these two measures: wetter $\left(\Delta A_{\mathrm{WB}}>0, \Delta N_{\mathrm{WB}}>0\right)$, drier $\left(\Delta A_{\mathrm{WB}}<0, \Delta N_{\mathrm{WB}}<0\right)$, fragmented $\left(\Delta A_{\mathrm{WB}}<0\right.$, $\left.\Delta N_{\mathrm{WB}}>0\right)$, and consolidated $\left(\Delta A_{\mathrm{WB}}>0\right.$, $\left.\Delta N_{\text {WB }}<0\right)$. Cities in the "wetter" category had larger area and numbers than their undeveloped landscapes. Conversely, cities in the "drier" category had smaller area and numbers than their undeveloped landscapes. Cities in the "fragmented" and "consolidated" categories had more complex differences. Cities in the "fragmented" category had smaller water body area, but larger numbers of water bodies, whereas cities in the "consolidated" category had a larger water body area, but were fewer in number. IBM SPSS v20 was used for all statistical procedures.

\section{Results \\ Hydrography of Undeveloped Land Cover}

This study included 1,048,365 water bodies, $1,380,638 \mathrm{~km}$ of flow paths, and a land area of $991,274 \mathrm{~km}^{2}$, which is approximately $11 \%$ of the land area in the contiguous United States. Surface water abundance in the undeveloped land of the MSAs followed expected broad scale trends in precipitation and topography (Figure 2). Water bodies in the mesic eastern US covered more area and were spatially denser than in the west, with regional highs along the coasts. MSAs in the Appalachian Mountains were an exception to this pattern, having minimal area $\left(A_{\mathrm{WB}}\right)$ and number $\left(N_{\mathrm{WB}}\right)$ of water bodies. Hereafter, we define "dry" regions with minimal surface water abundance to include both the arid southwest and mountainous regions, such as Appalachia. Channel density $\left(D_{\mathrm{C}}\right)$ followed a somewhat more complex spatial pattern related to topography, with the highest densities in mountainous regions and minimal density in flat

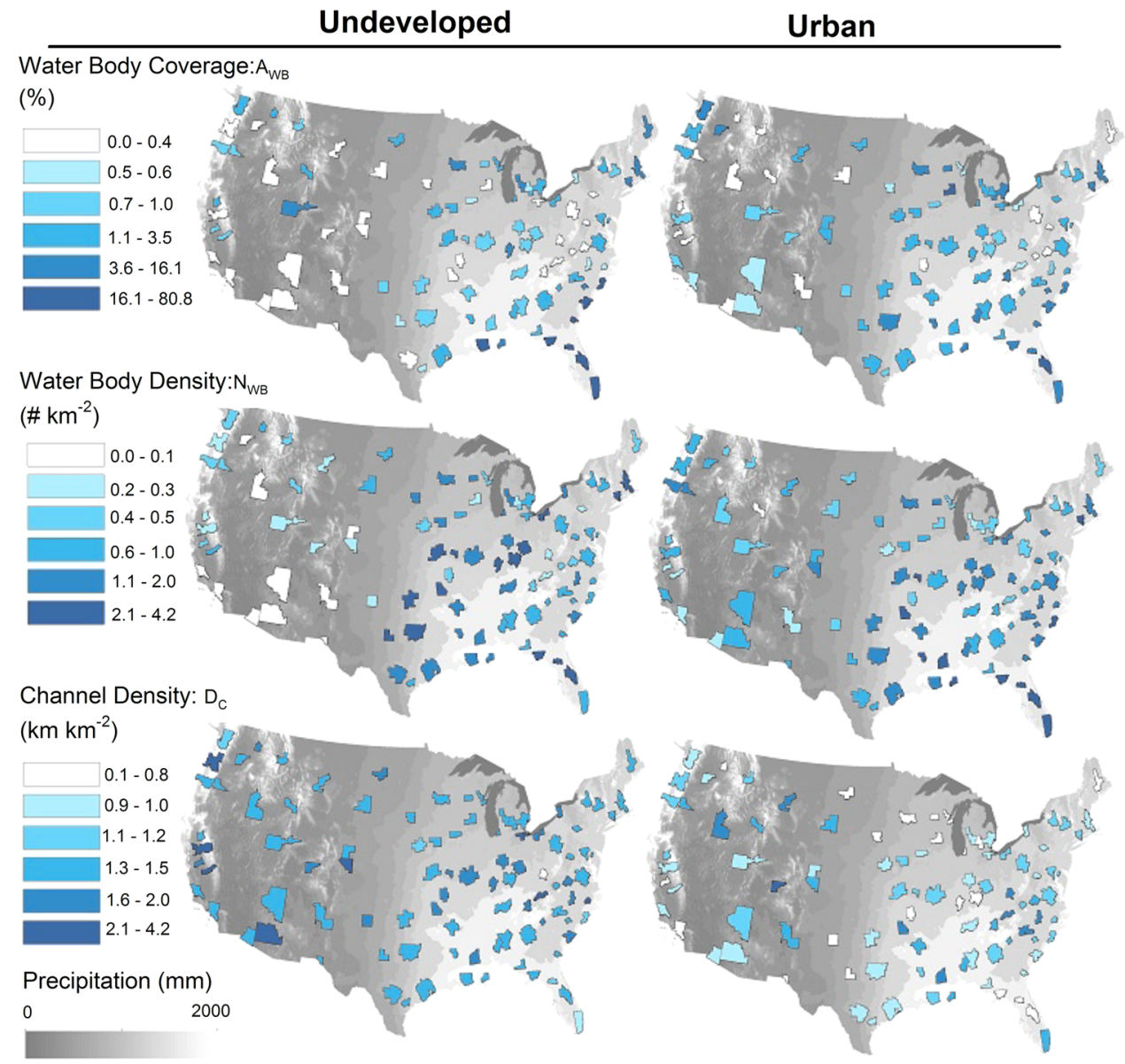

Figure 2. Map of 100 metropolitan statistical areas color coded by surface water abundance in undeveloped (without dams) and in urban land cover across the precipitation gradient of the United States. Parameters included the percent water body coverage $\left(A_{\mathrm{WB}}\right)$, the water body numeric density $\left(N_{\mathrm{WB}}\right)$, and the density of channel length $\left(D_{\mathrm{C}}\right)$, within each land cover type. 
coastal regions. The abundance of surface water features in the urban land cover of the MSAs only weakly followed the geographic patterns exhibited in undeveloped land (Figure 2).

\section{Evidence of Convergence}

The results show strong evidence of converging urban hydroscapes across the United States. The variance of urban $A_{\mathrm{WB}}, N_{\mathrm{WB}}$, and $D_{\mathrm{C}}$ across the 100 MSAs was lower, by 89,25 , and $71 \%$, respectively, compared to the variance of undeveloped land cover (Figure 3). The patterns of hydrographic convergence were also observed in the characteristics of urban water bodies. The variance of $S D_{\mathrm{wB}}$ decreased by $59 \%$ compared to the variance of the undeveloped land.

As urban development intensity increased the variance in $A_{\mathrm{WB}}$ and $N_{\mathrm{WB}}$ decreased. For example, the variance of $A_{\mathrm{WB}}$ decreased by $76 \%$ in open area and $98 \%$ in high intensity urban development compared to undeveloped lands. The decrease in variance coincided with a decrease in the median surface water abundance, suggesting the abundance on which hydrography is converging is lower than the median surface water abundance of the undeveloped land (Figure 3). Compared to undeveloped land, the median $A_{\mathrm{WB}}$ decreased by 47, 64, and $74 \%$ in low, medium, and high intensity urban land, respectively. A parallel trend was observed for $D_{C}$, which decreased by $28 \%$ in the low intensity and $48 \%$ in medium and high intensity urban land cover relative to undeveloped land. The variance of $D_{\mathrm{C}}$ remained relatively constant across the urban intensity classes, but was much less than the undeveloped $D_{\mathrm{C}}$ for all urban development intensities.

Consistent with our initial predictions, whether $\Delta A_{\mathrm{WB}}, \Delta N_{\mathrm{WB}}$, and $\Delta D_{\mathrm{C}}$ were positive or negative values was related to the $A_{\mathrm{WB}}, N_{\mathrm{WB}}$, and $D_{\mathrm{C}}$ in undeveloped land (Figure 4). For example, among cities in the driest landscapes $\left(<0.25 \% A_{\mathrm{WB}}\right.$ in undeveloped land) urban areas contained greater $A_{\mathrm{WB}}$ than surrounding lands in more than $90 \%$ of cases $(n=19)$. Conversely, no cities in the wettest landscapes $\left(>4 \% A_{\mathrm{WB}} ; n=13\right)$ showed net water addition. The observed value of $\Delta A_{\mathrm{WB}}, \Delta N_{\mathrm{WB}}$, and $\Delta D_{\mathrm{C}}$ roughly followed gradients in precipitation and topography. The dry cities tended to have modest positive $\Delta A_{\mathrm{WB}}$, whereas $\Delta A_{\mathrm{WB}}$ along the humid coast were largely negative. $\Delta N_{\mathrm{WB}}$ was negative in the Midwest and Great Plains states, whereas the rest of the country tended to have positive differences. $\Delta D_{\mathrm{C}}$ tended to be negative throughout much of the country.
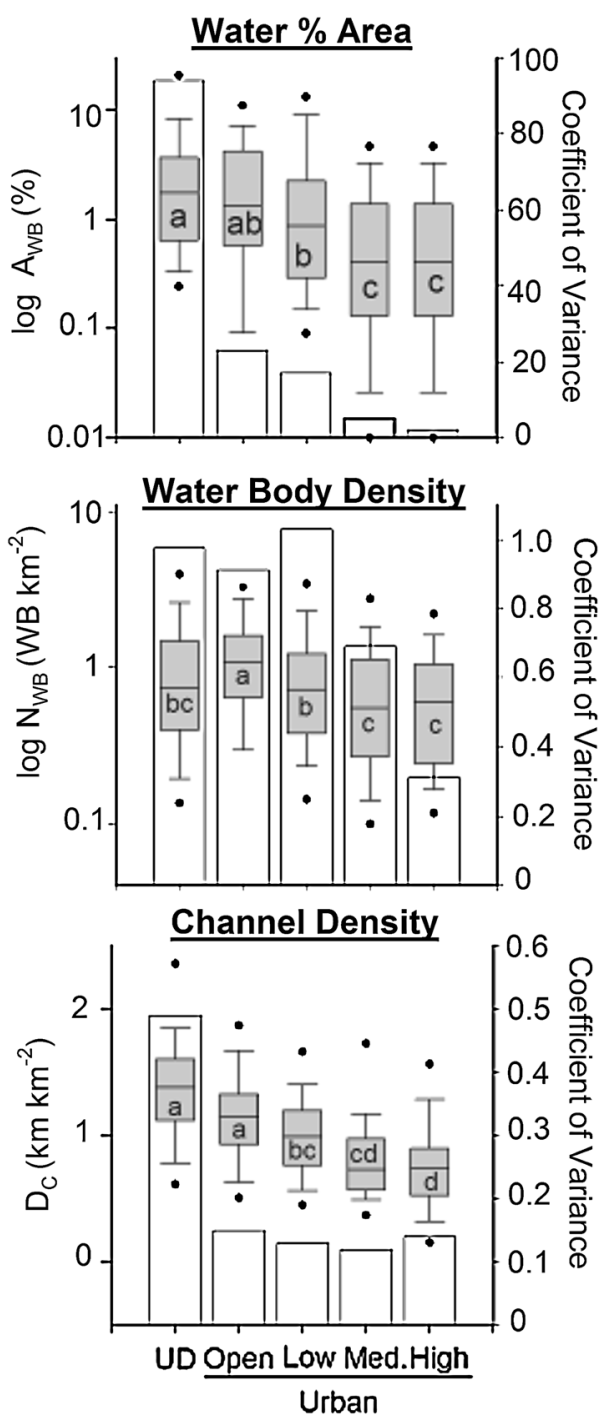

Figure 3. Water body and channel abundance with land cover. Boxplots are the surface water abundance as measured by percent water body coverage $\left(A_{\mathrm{WB}}\right)$, density of water bodies $\left(N_{\mathrm{WB}}\right)$, and channel density $\left(D_{\mathrm{C}}\right)$. Undeveloped (UD) land cover was compared with four classes of urban land cover: open area (Open), low intensity (Low), medium intensity (Med.), and high intensity (High). Letters designate significant differences among land cover categories at $p<0.05$. Bars represent the coefficient of variance for each land class.

As urban intensity increased, the distribution of urban $A_{\mathrm{WB}}, N_{\mathrm{WB}}$, and $D_{\mathrm{C}}$ became more tightly constrained, as measured by the range between the 25 and $75 \%$ quartiles $\left(R\left(Q_{1}, Q_{3}\right)\right)$ (Figure 5$)$. High intensity development was drier than other urban areas, and the association between undeveloped hydrography and urban-undeveloped differences were stronger (Figure 5). The urban median decreased for all parameters as intensity increased, indicating that denser urban developments are also 


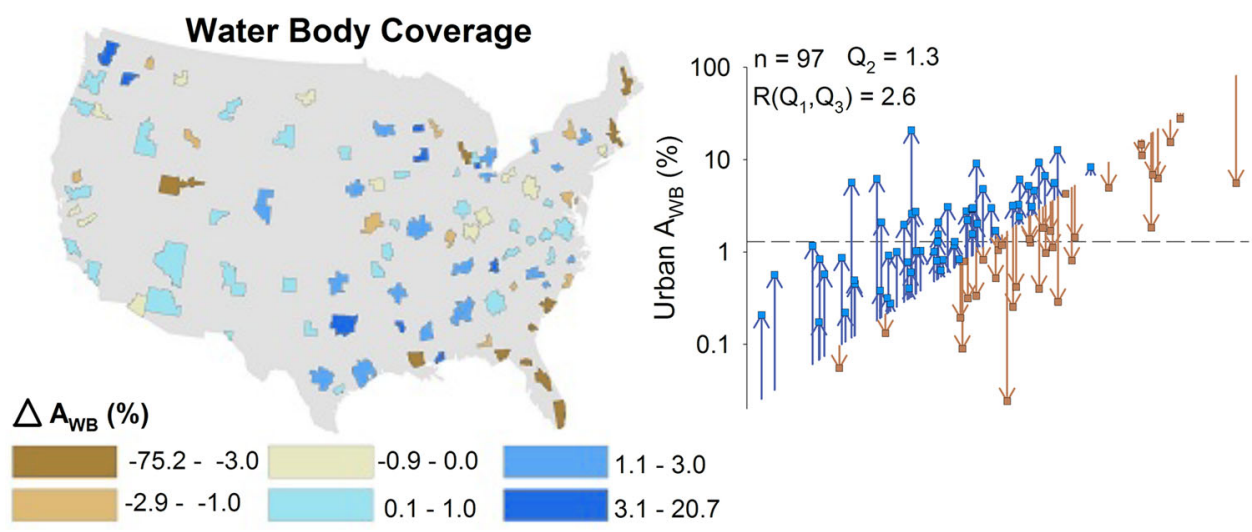

Figure 4. The relationship between urban and the undeveloped land surface water, including the number of MSAs $(n)$, the median $\left(Q_{2}\right.$, dashed line), and the range between the 25th and 75th quartiles $\left(R\left(Q_{1}, Q_{3}\right)\right)$ of the urban parameters. Squares represent the urban value, whereas arrows represent the direction (positive $=$ blue, negative $=$ brown ) and magnitude of difference between urban and its undeveloped counterpart. Individual MSAs are color coded by the difference in urban surface water. The symbols $\Delta A_{\mathrm{WB}}, \Delta N_{\mathrm{WB}}$, and $\Delta D_{\mathrm{C}}$ represent the urban minus undeveloped difference for water body areal coverage $\left(A_{\mathrm{WB}}\right)$, numeric density $\left(N_{\mathrm{WB}}\right)$, and channel density $\left(D_{\mathrm{C}}\right)$, respectively.

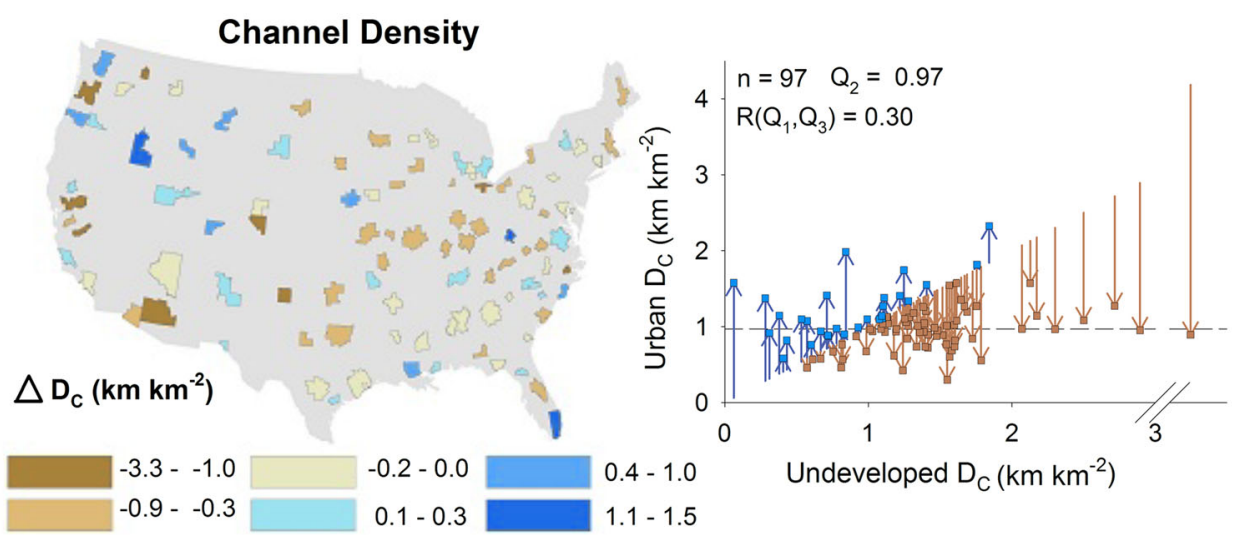

converging on a drier landscape. In other words, as a city develops higher density, patterns of surface water more closely resemble those of other cities rather than the surrounding landscape.

City size and the exclusion of either dams or agricultural land cover in the surrounding land had minimal impact on the results. The variance of all non-urban land was lower than that of the undeveloped land by 24,6 , and $18 \%$ for $A_{\mathrm{WB}}, N_{\mathrm{WB}}$, and $D_{\mathrm{C}}$, respectively; however, the variance of all non-urban land was still larger than the urban land covers. The variation in undeveloped land parameters was also very similar with and without dams.
Likewise, no differences were identified between the city size categories for any of hydrographic parameters, nor for the indicators of convergence (data not shown).

We did not observe a significant correlation between $\Delta A_{\mathrm{WB}}$ and $\Delta N_{\mathrm{WB}}$ (Figure 6). In other words, differences in the density of water bodies and in their aggregate area were essentially independent, and approximately equal numbers of urban areas fell into our four categories. MSAs in the wetter, fragmented, and consolidated categories were concentrated in the dry, coastal, and Midwest regions, respectively (Figure 6). Most of the cities 

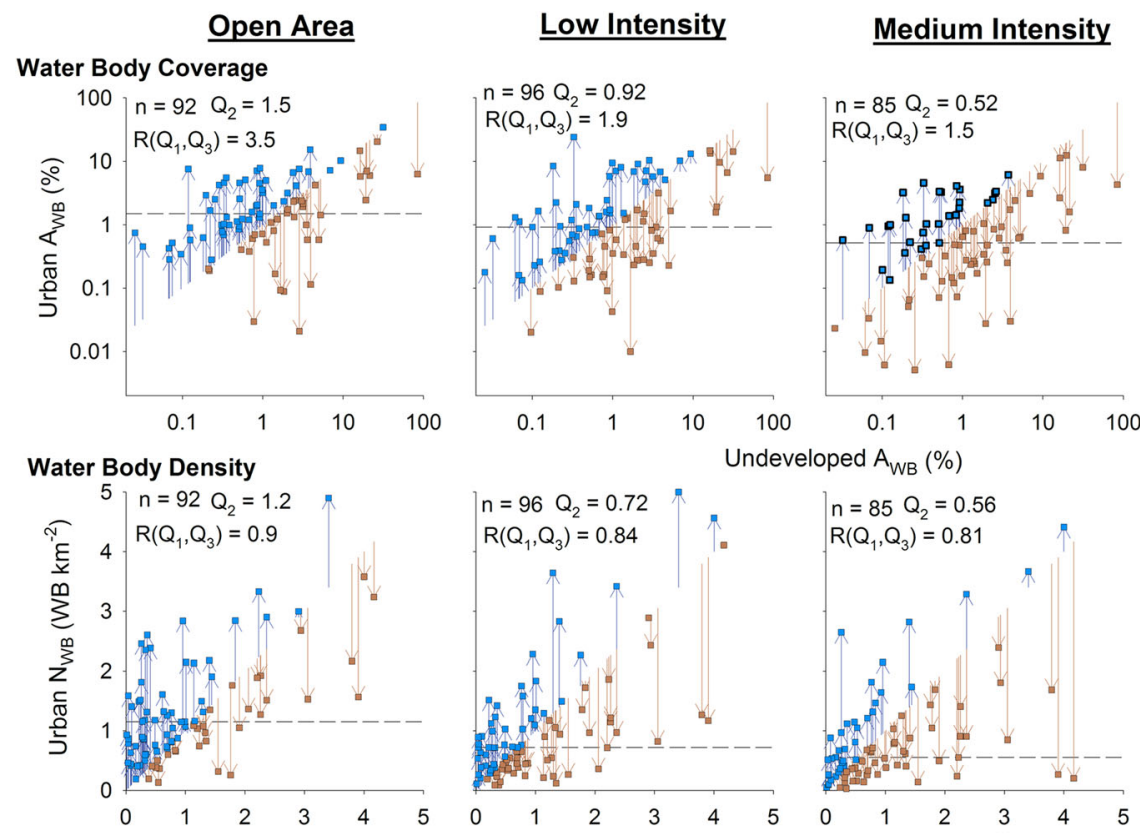

Channel Density

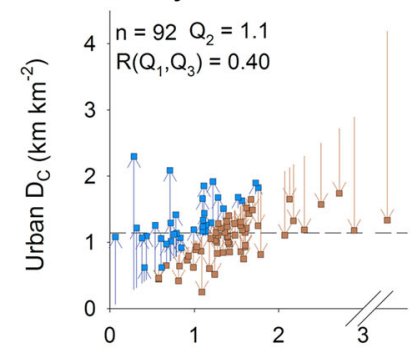

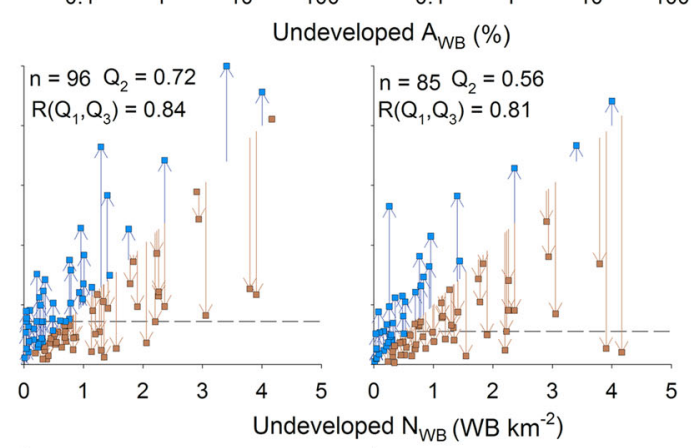
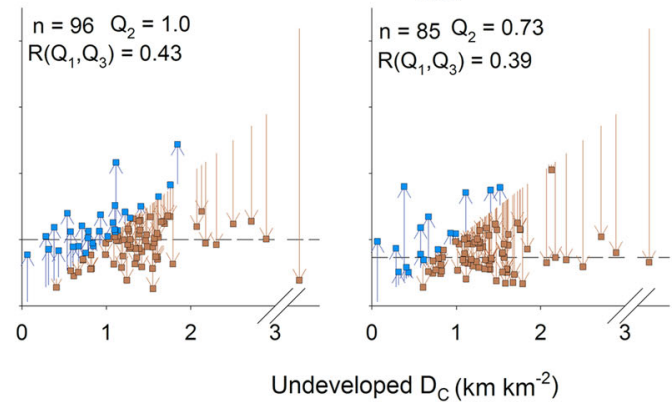

High Intensity
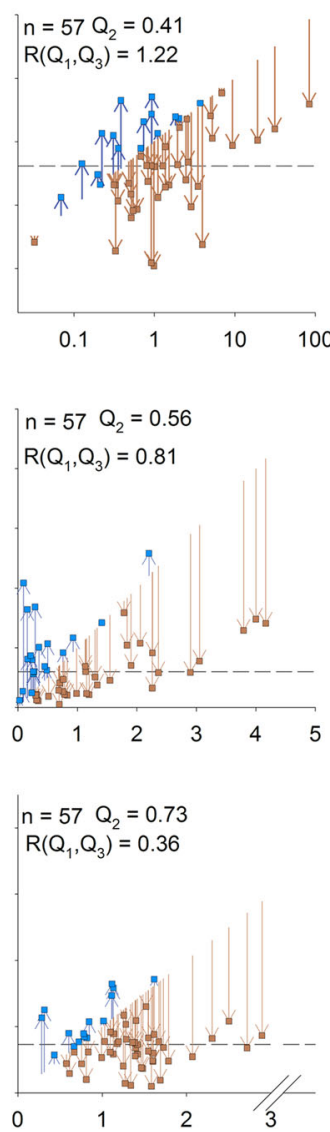

Figure 5. The relationship between urban intensity class and undeveloped land surface water, including the number of MSAs $(n)$, the median $\left(Q_{2}\right.$, dashed line $)$, and the range between the 25 th and 75 th quartiles $\left(R\left(Q_{1}, Q_{3}\right)\right)$ of water body areal coverage $\left(A_{\mathrm{WB}}\right)$, numeric density $\left(N_{\mathrm{WB}}\right)$, and channel density $\left(D_{\mathrm{C}}\right)$ respectively. Squares represent the urban value, whereas arrows represent the direction (positive $=$ blue, negative $=$ brown) and magnitude of difference between urban and its undeveloped counterpart.

with negative differences in both area and number of water bodies were in the north-east and midwest, but the geographic pattern of drier cities was not as well defined.

\section{Discussion}

\section{Converging Urban Hydroscapes}

Based on patterns in US cities, we conclude that urbanization causes the convergence of surface water abundance at broad scales. Surface water abundance in the undeveloped land of this study followed previously observed continental scale patterns in hydrography (Downing and others 2006); however, the surface water abundance of the urban landscapes did not conform to these hydrographic patterns. Continental scale variation among urban hydroscapes was far less than variation between undeveloped hydroscapes. In addition, the extent and direction of differences between urban and surrounding undeveloped hydrography appear to be related to the broad geographic patterns in climate and topography. Urban land in dry regions had greater abundances of surface water than surrounding undeveloped land, whereas urban land in very wet regions had lower abundances of surface water than their surroundings. Only by examining patterns at broad spatial scales are we able to understand the role of climatic, physiographic, and anthropogenic drivers of surface water distributions (Heffernan and others 2014; Thorp 2014).

The convergence of surface water abundance may also cause the convergence of surface water 

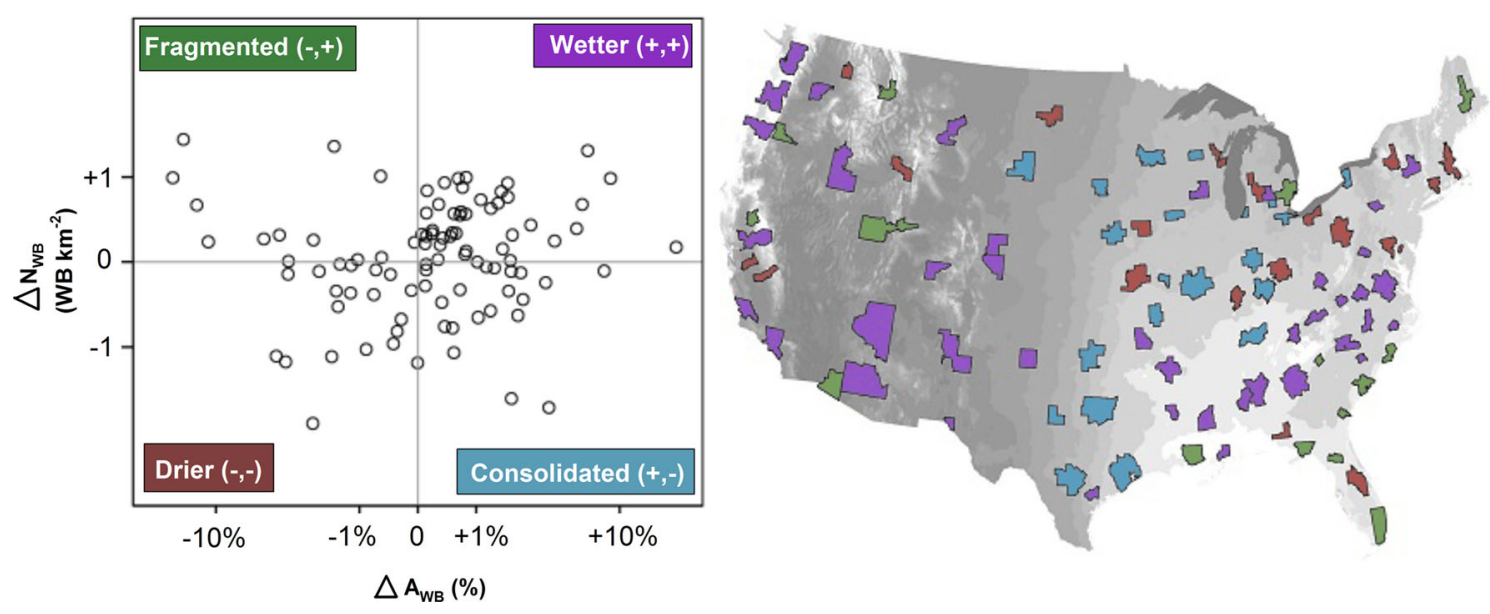

Figure 6. Relationship between the difference in urban water body coverage $\left(\Delta A_{\mathrm{WB}}\right)$ and the difference in water body numeric density $\left(\Delta N_{\mathrm{WB}}\right)$. Grey lines indicate the zero difference. MSAs are color coded to match the label color of the four categories (fragmented, wetter, drier, and consolidated).

characteristics. Previous studies on urban stream loss document a preferential loss of smaller water features (Elmore and Kaushal 2008; Roy and others 2009; Larson and Grimm 2012). Urban water bodies tend to be more moderately sized and less connected to surface channels than their counterparts in undeveloped lands (Steele and Heffernan 2014). These differences in physical form may reflect the relative change in removal costs and value with size, certain functional needs, or aesthetic preferences. As a whole, the convergence of water body sizes suggests a reshaping of urban hydroscapes that is more pervasive and nuanced than simply adding or removing surface water from the landscape.

This study adds to the growing evidence that urbanization is a homogenizing process (Groffman and others 2014). Although cities are highly heterogeneous at local scales (Cadenasso and others 2007), the standardization of design, construction, and land use creates urban ecosystems that are broadly similar across large regions (Pouyat and others 2003, 2007; Pickett and others 2011; Seto and others 2012). Such similarities lead to urban growth and development patterns that converge toward a specific form (Seto and Fragkias 2005; Batty 2008). Ecological communities in cities are homogenized by the intentional and accidental shuffling of flora and fauna by commerce and through planting, which introduces a common pool of cosmopolitan species to similarly structured urban environments (McKinney 2006; Lososová and others 2012). Our data suggest that homogenization of urban environments extends beyond changes in land cover and species composition to include transformation of the land's shape, and indeed, whether it is even dry land at all.

\section{Urban Development Intensity and City Size}

As predicted, increasing development intensity led to greater convergence of surface water abundance. We primarily attribute this pattern to the increased value of dry land for building, where land is scarce and demand for development is high. Alternatively, this pattern may also reflect a legacy of land use. Most urban cores in the US were established as centers of business and industrial production, activities for which water bodies and streams are of little use or value. As manufacturing industries relocate and city centers develop service oriented economies with larger residential populations and mixed land uses, we may observe a reincorporation of surface water into high density development. Surface water, such as park ponds and streams, serve as recreational amenities for urban residents and tourists and therefore are likely more highly valued in this type of urban center (Abbott and Klaiber 2013). Regardless of the drivers, it is important to note that the difference between urban and undeveloped land was far greater than the differences between the intensity classes for both water body coverage and channel density. Given that most urban development is low intensity, the majority of surface water in a city may still be substantially different than its original condition.

This study provides a unique examination of urbanization across a large number of cities and range of population sizes. Although many aspects 
of cities vary predictably with population (Bettencourt and others 2007), we find the population of cities only indirectly affects hydrographic characteristics. Cities with smaller populations tended to lack the high intensity urban development, where observed changes were most pronounced and covered smaller areas; however, the hydrography of other land cover types (open, low, and medium intensity) was indistinguishable between large and small cities. This finding is important given that the number of small towns far exceeds the number of large cities. Thus any positive or negative effects resulting from urban hydrographic convergence will affect a much larger, extensive area.

\section{Shaping the Urban Hydroscape: Regional Patterns and Mechanisms}

In both absolute terms and relative to lands surrounding cities, urban hydroscapes are both structurally and spatially complex, and exhibit strong geographic patterns. When the differences in both water body number and areal coverage for each MSA were observed in tandem, cities with minimal surface water abundance tended to have both a larger areal coverage and numeric density, although a few exceptions did not follow this pattern. Across the rest of the US, a large number of cities fell into the fragmented or consolidated categories. Cities in the fragmented category $\left(\Delta A_{\mathrm{WB}}<0\right.$, $\Delta N_{\mathrm{WB}}>0$ ) were mostly located along the southern coastline, where expansive areas of wetlands are prominent in undeveloped lands. In comparison, the urban water bodies covered less area, but were greater in number. This fragmented pattern may reflect the drainage and breakup of these wetland tracts, as observed in case studies (Du and others 2010), or may reflect selection of sites around or between those features. The compensatory mitigation of wetland losses predominantly leads to wetland reconstruction outside of the affected watersheds (Kettlewell and others 2008). Similarly, large reservoirs that serve as municipal water supplies and flood control are often located outside of developed areas. In effect, relocation accumulates and consolidates water lost within the urban core elsewhere, but at this time its contribution to the observed patterns is unknown.

The consolidated pattern was particularly strong in the Midwest and Plains cities. Here water bodies in the urban land covered a larger area, but were fewer in number compared to those in undeveloped landscapes. Although we tried to minimize the presence of other land covers within the undeveloped area, it is possible that the consoli- dation pattern of the mid-section of the US reflects a legacy of agricultural development in the undeveloped land cover. Artificial drainage and the presence of agricultural farm ponds could generate a pattern of small areal coverage and high numbers of water bodies (Skaggs and others 1994; Downing and others 2006). Though we cannot determine agriculture's contribution to these patterns with certainty, we still observe convergence at the US scale even when agriculture is included in the surrounding land estimate. This result suggests that urban hydrography is not simply inherited from an agricultural legacy, and highlights the need for investigation of agricultural hydrography at macroscales, as well as how and where urban development incorporates or alters those characteristics.

Urban hydrographic patterns likely reflect two main mechanisms: alteration and choice of location for building. Alteration includes construction, removal, or relocation of surface water features during urban development. Direct observation from previous, more detailed case studies of urban hydrographic change (Elmore and Kaushal 2008; Roy and others 2009; Du and others 2010; Larson and Grimm 2012) suggests that hydrographic alteration is a dominant mechanism of change in some cities. An alternative explanation for the hydrographic patterns we observed is that cities are selectively built in areas with particular hydrographic characteristics. Arid cities, for example Phoenix, are often built along rivers and other locally "wet" areas within the arid landscape that could account for the apparent increase in surface water abundance. Many cities are built on major rivers or the shorelines of major water bodies and the tendency to build in very similar locations may contribute to overall similarities in hydrographic pattern.

The relative role of the mechanisms of hydrographic change, like other land use and land cover changes, is likely spatially and temporally heterogeneous. Spatial heterogeneity in the mechanisms may be correlated with the figurative distance of a city from the convergence point. For example, cities built in regions at the extremes of surface water abundance may require more substantial alteration (for example, Phoenix, Miami, Houston). In addition, the role of these mechanisms is also likely temporally heterogeneous. The distribution of the types of water bodies in cities of different sizes suggests selection may be more important in the initial stages of cities and changes as cities grow outward from their original settlements (Steele and Heffernan 2014). A case study of water bodies in Phoenix, wherein the initial settlement was located 
along a locally wet riparian area, supports the idea of temporal variation. As the city has grown outward, the density of built water bodies has increased, and the structure of watered lands has changed from one linearly centered along rivers and riparian areas toward more expansive watered landscapes that serve urban and residential purposes (Larson and Grimm 2012). It is important to mention, however, that using a space for time substitution limits our ability to draw inferences regarding how the hydrography of cities changes.

\section{Implications for Ecosystems and Management}

A number of ecological and ecosystem processes are mediated by the abundance of surface water and its geomorphology. The abundance of lakes, ponds, wetlands, and streams, as well as the size of water bodies and the connectivity between these features, mediates watershed fluxes of carbon, nitrogen, and phosphorus (Cole and others 2007; Fraterrigo and Downing 2008; Downing 2010) in addition to species abundance and distribution (Dunham and Rieman 1999; Dahlgren and Ehrlen 2005). Further research will be needed to determine if the convergence of urban hydrography leads to a convergence of biogeochemical and ecosystem properties related to the surface water abundance and characteristics. Some urban watersheds, for example those in coastal areas, may function very differently than the original ecosystem. For others, the differences in the hydroscape structure may be of little consequence to local ecosystems relative to the effects of pollution and other changes associated with urbanization.

Though the urban hydroscape is converging, this does not indicate that the management of urban watersheds should be likewise homogeneous. Cities manage surface water to supply a host of services as well as mitigate the negative consequences of an overabundance of water (for example, flooding, mosquitoes) or aridity (for example, scarcity, heat). We can only speculate about the extent to which the convergent pattern represents an optimization of services provided by surface water; however, increasing these benefits is likely to remain a continuing goal of landscape design and development. Depending on the service, some cities may benefit from returning to a hydroscape more closely resembling the antecedent one, whereas others may benefit from a further departure. For example, small water bodies in the urban landscape more efficiently regulate microclimates (Sun and others 2012; Sun and Chen 2012) and incorporation or reestablish- ment of small water bodies in cities may provide cooling benefits within the urban heat island and energy savings. For some cities that may have removed a significant portion of the small water bodies, this re-establishment would return the city to a hydroscape more similar to the antecedent one; however, for cities such as Phoenix, such perennial features would present a further departure.

Hydrographic patterns reflect the interaction between geophysical constraints and the policies and practices of diverse decision makers whose decisions shape water management, stream and wetland conservation, and urban land use and land cover change at a variety of scales (Roy Chowdhury and others 2011). At broad scales, these multiscaled decisions lead to a configuration of urban development in the United States that is less dense and sprawling relative to cities elsewhere (Huang and others 2007; Schneider and Woodcock 2008). Higher density development in this study increased the convergence of urban surface water on a "drier" hydroscape relative to lower densities. Whether similar patterns occur in more consolidated, densely built regions of the globe might indicate how different priorities and constraints shape relationships among people, water, and the built environment across a wide range of political, economic, and environmental conditions.

\section{ConClusions}

Differences between urban and undeveloped hydrography reveal the environmental context of surface water abundance. We observed lower variance in surface water abundance parameters amongst urban lands than amongst their undeveloped counterpart, converging on a central value. Urbanization results in a tightly constrained range of urban hydrographic characteristics, at least within US cities. As such, the loss of spatial heterogeneity across the country indicates that the built environment may be a stronger predictor of the abundance of surface water features than climate and topography, two of the most fundamental drivers of large-scale patterns in nature.

\section{ACKNOWLEDGEMENTS}

We thank Emily Bernhardt, Martin Doyle, Jacqueline Aitkenhead-Peterson, Allison Appling, and the anonymous reviewers for helpful comments on earlier drafts of this manuscript. This research was supported by grants from the National Science Foundation's Macrosystems Biology program (NSF EF \#1065785). 


\section{OPEN ACCESS}

This article is distributed under the terms of the Creative Commons Attribution License which permits any use, distribution, and reproduction in any medium, provided the original author(s) and the source are credited.

\section{REFERENCES}

Abbott JK, Klaiber AH. 2013. The value of water as an urban club good: a matching approach to community-provided lakes. J Environ Econ Manag 65:208-24.

Army Corps of Engineers. 2013. National inventory of dams. Sausalito: US Army Corps of Engineers.

Batty M. 2008. The size, scale, and shape of cities. Science 319:769-71.

Bettencourt LM, Lobo J, Helbing D, Kuhnert C, West GB. 2007. Growth, innovation, scaling, and the pace of life in cities. Proc Natl Acad Sci USA 104:7301-6.

Bolund P, Hunhammar S. 1999. Ecosystem services in urban areas. Ecol Econ 29:293-301.

Cadenasso ML, Pickett ST, Schwarz K. 2007. Spatial hetrogeneity in urban ecosystems: reconceptualizing land cover and a framework for classification. Frontiers Ecol Environ 5:80-8.

Census Bureau. 2012. Metropolitan and micropolitan statistical areas. Washington, DC: Census Bureau.

Cohen JE. 2003. Human population: the next half century. Science 302:1172-5.

Cole JJ, Prairie YT, Caraco NF, McDowell WH, Tranvik LJ, Striegl RG, Duarte CM, Kortelainen P, Downing JA, Middelburg JJ, Melack J. 2007. Plumbing the global carbon cycle: integrating inland waters into the terrestrial carbon budget. Ecosystems 10:172-85.

Dahlgren JP, Ehrlen J. 2005. Distribution patterns of vascular plants in lakes-the role of metapopulation dynamics. Ecography 28:49-58.

Downing JA. 2010. Emerging global role of small lakes and ponds: little things mean a lot. Limnetica 29:9-24.

Downing JA, Prairie YT, Cole JJ, Duarte CM, Tranvik LJ, Striegl RG, McDowell WH, Kortelainen P, Caraco NF, Melack JM, Middleburg JJ. 2006. The global abundance and size distribution of lakes, ponds, and impoundments. Limnol Oceanogr 51:2388-97.

Du N, Ottens H, Sliuzas R. 2010. Spatial impact of urban expansion on surface water bodies-a case study of Wuhan, China. Landsc Urban Plan 94:175-85.

Dunham JB, Rieman BE. 1999. Metapopulation structure of bull trout: influence of physical, biotic, and geometrical landscape characteristics. Ecol Appl 9:642-55.

Dunne T, Leopold LB. 1978. Water in environmental planning. San Francisco: WH Freeman.

Elmore AJ, Kaushal SS. 2008. Disappearing headwaters: patterns of stream burial due to urbanization. Frontiers Ecol Environ 6:308-12.

Foley JA, Defries R, Asner GP, Barford C, Bonan G, Carpenter SR, Chapin FS, Coe MT, Daily GC, Gibbs HK, Helkowski JH, Holloway T, Howard EA, Kucharik CJ, Monfreda C, Patz JA, Prentice IC, Ramankutty N, Snyder PK. 2005. Global consequences of land use. Science 309:570-4.
Fraterrigo JM, Downing JA. 2008. The influence of land use on lake nutrients varies with watershed transport capacity. Ecosystems 11:1021-34.

Grimm NB, Faeth SH, Golubiewski NE, Redman CL, Wu J, Bai X, Briggs JM. 2008a. Global change and the ecology of cities. Science 319:756-60.

Grimm NB, Foster D, Groffman P, Grove JM, Hopkinson CS, Nadelhoffer KJ, Pataki DE, Peters DPC. 2008b. The changing landscape: ecosystem responses to urbanization and pollution across climatic and societal gradients. Frontiers Ecol Environ 6:264-72.

Groffman PM, Cavender-Bares J, Bettez ND, Grove JM, Hall SJ, Heffernan JB, Hobbie SE, Larson KL, Morse JL, Neill C, Nelson K, O'Neil-Dunne J, Ogden L, Pataki DE, Polsky C, Roy Chowdhury R, Steele MK. 2014. Ecological homogenization of urban America. Frontiers Ecol Environ 12(1):74-81.

Hamer A, Parris KM. 2011. Local and landscape determinants of amphibian communities in urban ponds. Ecol Appl 21:378-90.

Heffernan JB, Soranno P, Angilletta M, Buckley L, Gruner D, Keitt T, Kellner J, Kominoski J, Rocha A, Xiao J, Harms TK, Goring S, Koenig L, McDowell WH, Powell H, Richardson A, Stow C, Vargas R, Weathers KC. 2014. Macrosystems ecology: understanding ecological pattern and process at continental scales. Frontiers Ecol Environ 12(1):5.

Huang J, Lu XX, Sellers JM. 2007. A global comparative analysis of urban form: applying spatial metrics and remote sensing. Landsc Urban Plan 82:184-97.

Kareiva PW, Sean McDonald R, Boucher T. 2007. Domesticated nature: shaping landscapes and ecosystems for human welfare. Science 316:1866-9.

Kettlewell CI, Bouchard V, Porej D, Micacchion M, Mack J, White D, Fay L. 2008. An assesment of wetland impacts and compensatory mitigation in the Cuyahoga River Watershed, Ohio, USA. Wetlands 28:57-67.

Larson EK, Grimm NB. 2012. Small-scale and extensive hydrogeomorphic modification and water redistribution in a desert city and implications for regional nitrogen removal. Urban Ecosyst 15:71-85.

Lososová Z, Chytrý M, Tichý L, Danihelka J, Fajmon K, Hájek O, Kintrová K, Láníková D, Otýpková Z, Řehořek V. 2012. Biotic homogenization of Central European urban floras depends on residence time of alien species and habitat types. Biol Conserv 145:179-84.

McKinney ML. 2006. Urbanization as a major cause of biotic homogenization. Biol Conserv 127:247-60.

McKinney RA, Raposa KB, Cournoyer RM. 2011. Wetlands as habitat in urbanizing landscapes: patterns of bird abundance and occupancy. Landsc Urban Plan 100:144-52.

NEON. 2010. Field site and sampling strategy.

Pataki DE, Boone CG, Hogue TS, Jenerette GD, McFadden JP, Pincetl S. 2011. Socio-ecohydrology and the urban water challenge. Ecohydrology 4:341-7.

Paul MJ, Meyer JL. 2001. Streams in the urban landscape. Ann Rev Ecol Syst 32:333-65.

Pickett ST, Cadenasso ML, Grove JM, Boone CG, Groffman PM, Irwin E, Kaushal SS, Marshall V, McGrath BP, Nilon $\mathrm{CH}$, Pouyat RV, Szlavecz K, Troy A, Warren P. 2011. Urban ecological systems: scientific foundations and a decade of progress. J Environ Manag 92:331-62.

Pouyat RV, Pataki DE, Belt KT, Groffman PM, Hom J, Band LE. 2007. Effects of urban land-use change on biogeochemical 
cycles. In: Canadell JG, Pataki DE, Pitelka LF, Eds. Terrestrial ecosystems in a changing world. Berlin: Springer. p 45-58.

Pouyat RV, Russell-Anelli J, Yesilonis ID, Groffman PM. 2003. Soil carbon in urban forest ecosystems. In: Kimble J, Ed. Potential of United States forest soils to sequester carbon and mitigate the greenhouse effect. Boca Raton: CRC Press. p 34760.

Roy AH, Dybas AL, Fritz KM, Lubbers HR. 2009. Urbanization affects the extent and hydrologic permanence of headwater streams in a midwestern US metropolitan area. J N Am Benthol Soc 28:911-28.

Roy Chowdhury R, Larson K, Grove JM, Polsky C, Cook E. 2011. A multi-scalar approach to theorizing socio-ecological dynamics of urban residential landscapes. Cities Environ 4:119.

Schneider A, Woodcock CE. 2008. Compact, dispersed, fragmented, extensive? A comparison of urban growth in twentyfive global cities using remotely sensed data, pattern metrics and census information. Urban Stud 45:659-92.
Seto KC, Fragkias M. 2005. Quantifying spatiotemporal patterns of urban land-use change in four cities of china with time series landscape metrics. Landsc Ecol 20:871-88.

Seto KC, Reenberg A, Boone CG, Fragkias M, Haase D, Langanke T, Marcotullio P, Munroe DK, Olah B, Simon D. 2012. Urban land teleconnections and sustainability. Proc Natl Acad Sci 109:7687-92.

Skaggs RW, Breve MA, Gilliam JW. 1994. Hydrologic and water quality impacts of agricultural drainage. Crit Rev Environ Sci Technol 24:1-32.

Steele MK, Heffernan JB. 2014. Morphological characteristics of urban water bodies: mechanisms of change and implications for ecosystem function. Ecol Appl. doi:10.1890/13-0983.1.

Sun R, Chen A, Chen L, Lü Y. 2012. Cooling effects of wetlands in an urban region: the case of Beijing. Ecol Indic 20:57-64.

Sun R, Chen L. 2012. How can urban water bodies be designed for climate adaptation? Landsc Urban Plan 105:27-33.

Thorp JH. 2014. Metamorphosis in river ecology: from reaches to macrosystems. Freshw Biol 59:200-10. 